\title{
Flexible fibreoptic intubation in swine - improvement for resident training and animal safety alike
}

\author{
Robert Ruemmler ${ }^{*}$ (D, Alexander Ziebart, Thomas Ott, Dagmar Dirvonskis and Erik Kristoffer Hartmann
}

\begin{abstract}
Background: Efficient airway management to facilitate tracheal intubation encompasses essential skills in anaesthesiologic and intensive care. The application of flexible fibreoptic intubation in patients with difficult airways has been identified as the recommended method in various international guidelines. However, providing the opportunity to adequately train residents can be challenging. Using large animals for practice during ongoing studies could help to improve this situation, but there is no recent data on fibreoptic intubation in swine available.

Methods: Thirty male German landrace pigs were anesthetized, instrumented and randomized into two groups. The animals were either intubated conventionally using direct laryngoscopy or a single-use flexible videoendoscope. The intervention was carried out by providers with 3 months experience in conventional intubation of pigs and a brief introduction into endoscopy. Intubation attempts were supervised and aborted, when SpO2 dropped below 93\%. After three failed attempts, an experienced supervisor intervened and performed the intubation. Intubation times and attempts were recorded and analysed.
\end{abstract}

Results: Flexible fibreoptic intubation showed a significantly higher success rate in first attempt endotracheal tube placement ( $75 \%$ vs. $47 \%)$ with less attempts overall ( $1.3 \pm 0.6$ vs. $2.1 \pm 1.3, P=0.043)$. Conventional intubation was faster ( $42 \mathrm{~s} \pm 6 \mathrm{~s}$ vs. $67 \mathrm{~s} \pm 10 \mathrm{~s}, P<0.001$ ), but showed a higher complication rate and more desaturation episodes during the trial.

Conclusions: Flexible fibreoptic intubation in swine is feasible and appears to be a safer and more accessible method for inexperienced users to learn. This could not only improve resident training options in hospitals with animal research facilities but might also prevent airway complications and needless animal suffering.

Keywords: Airway management, Animal safety, Difficult airway, Fibreoptic intubation, Resident training

\section{Background}

The efficient and safe airway management is one of the most important and outcome-relevant anaesthesiologic skills and directly affects perioperative mortality [1-4]. Flexible fibreoptic intubation (FFI) is recommended in national guidelines in the condition of an anticipated difficult airway [5-7] as well as a method amongst

\footnotetext{
* Correspondence: Robert.ruemmler@email.de

Department of Anaesthesiology, Medical Centre of the Johannes

Gutenberg-University, Langenbeckstrasse 1, 55131 Mainz, Germany
}

others in the unanticipated difficult airway $[3,5,6]$ in order to safely facilitate tracheal tube placement in humans.

By comparison, while actual lung physiology is similar to humans and is regularly used for translational research in anaesthesiologic experiments [8], the airway management of swine can be challenging due to special anatomic properties on the orotracheal level [9-11]. The rate of encountered airway problems, resulting mortality or negative experimental effects in swine has not been sufficiently

(c) The Author(s). 2020 Open Access This article is licensed under a Creative Commons Attribution 4.0 International License, which permits use, sharing, adaptation, distribution and reproduction in any medium or format, as long as you give appropriate credit to the original author(s) and the source, provide a link to the Creative Commons licence, and indicate if changes were made. The images or other third party material in this article are included in the article's Creative Commons licence, unless indicated otherwise in a credit line to the material. If material is not included in the article's Creative Commons licence and your intended use is not permitted by statutory regulation or exceeds the permitted use, you will need to obtain permission directly from the copyright holder. To view a copy of this licence, visit http://creativecommons.org/licenses/by/4.0/ The Creative Commons Public Domain Dedication waiver (http://creativecommons.org/publicdomain/zero/1.0/) applies to the data made available in this article, unless otherwise stated in a credit line to the data. 
reported but is frequently mentioned [12-14]. Accordingly, in terms of clinical assessment, swine may inhere an anticipated difficult airway, thus warranting the search for alternative strategies to secure tracheal tube placement. Subsequently, FFI could be a promising option to preserve positive trial outcomes without unnecessary animal losses.

However, the adequate establishment and maintenance of crucial technical skills concerning FFI often poses organisational and structural problems in the reality of clinical practice and hospital environments [15, 16]. Although the use of large animal models has been suggested and was rated superior to manikin-based simulations [17], no further prospective examinations in the field have been conducted since and porcine models are not implemented in standard training protocols to date.

In this prospective randomized pilot trial, we evaluated the feasibility and effectiveness of video-enhanced FFI by inexperienced providers in swine compared to conventional intubation (CI), while simultaneously assessing complication rates during orotracheal intubation. We hypothesized that the use of FFI would show a higher success rate and therefore provide a safer tracheal access than direct laryngoscopy. Specifically, we assessed intubation attempts necessary as well as the time needed to successfully secure the airway. Additionally, we discuss whether porcine models can be used as a training tool for FFI and the maintenance of proficiency in this technique.

\section{Methods}

\section{Anaesthesia}

The study was approved by the State and Institutional Animal Care Committee (Landesuntersuchungsamt Rheinland-Pfalz, Koblenz, Germany, approval no. G161-042) with an additional approval (Issue date: 8/28/ 2019) for the dual use of the animals in this protocol. Thirty male German landrace pigs (12-16 weeks, 28-35 $\mathrm{kg}$ ) were acquired from a local farm and received pretransport sedation via an intramuscular injection of azaperone $\left(2 \mathrm{mg} \mathrm{kg}^{-1}\right)$ and ketamine $\left(4 \mathrm{mg} \mathrm{kg}^{-1}\right)$. Once in our Large Animal Research Facility, anaesthesia was induced via an ear cannula (22G) by injecting fentanyl $\left(4 \mathrm{\mu g} \mathrm{kg}^{-1}\right)$, propofol $\left(4 \mathrm{mg} \mathrm{kg}^{-1}\right)$ and atracurium $(0.5$ $\left.\mathrm{mg} \mathrm{kg}^{-1}\right)$ as described before [18]. During the whole experiment, anaesthesia was maintained via continuous infusion of propofol (5-10 $\left.\mathrm{mg} \mathrm{kg}^{-1} \mathrm{~h}^{-1}\right)$ and fentanyl (8$12 \mu \mathrm{g} \mathrm{kg}^{-1} \mathrm{~h}^{-1}$ ) as well as a balanced electrolyte infusion $\left(5 \mathrm{ml} \mathrm{kg}^{-1} \mathrm{~h}^{-1}\right)$. The animals were transferred into a supine position and mechanically ventilated with a custom ventilation nose cone [19] using an intensive care respirator (Engstroem care station, GE healthcare, Munich; tidal volume $6-8 \mathrm{ml} / \mathrm{kg}$, peak inspiratory pressure of $40 \mathrm{cmH}_{2} \mathrm{O}$, positive end expiratory pressure of $5 \mathrm{cmH}_{2} \mathrm{O}$ ). Adequate ventilation was confirmed by capnography, peripheral oxygen saturation and auscultation of the thorax.

\section{Intervention/ measurements}

After $4 \mathrm{~min}$ of mask ventilation, the epiglottis of the swine was mobilized from the soft palate by the supervisor (Fig. 1) using a Macintosh blade (size 4) as well as a tube guiding rod and performing a careful scooping motion from the right piriform recess to the left along the soft palate. After the dislodgement was visually confirmed, the animals were randomized into two groups:

CI group (conventional intubation): Animals were intubated via direct laryngoscopy using a MacIntosh blade (size \#4, large) and a standard tracheal tube (TT, internal diameter (ID) $7.0 \mathrm{~mm}$ ).

FFI group (flexible fibreoptic intubation): Animals were intubated using a single-use endoscope with video monitoring (Ambu aScope regular and Ambu aView,

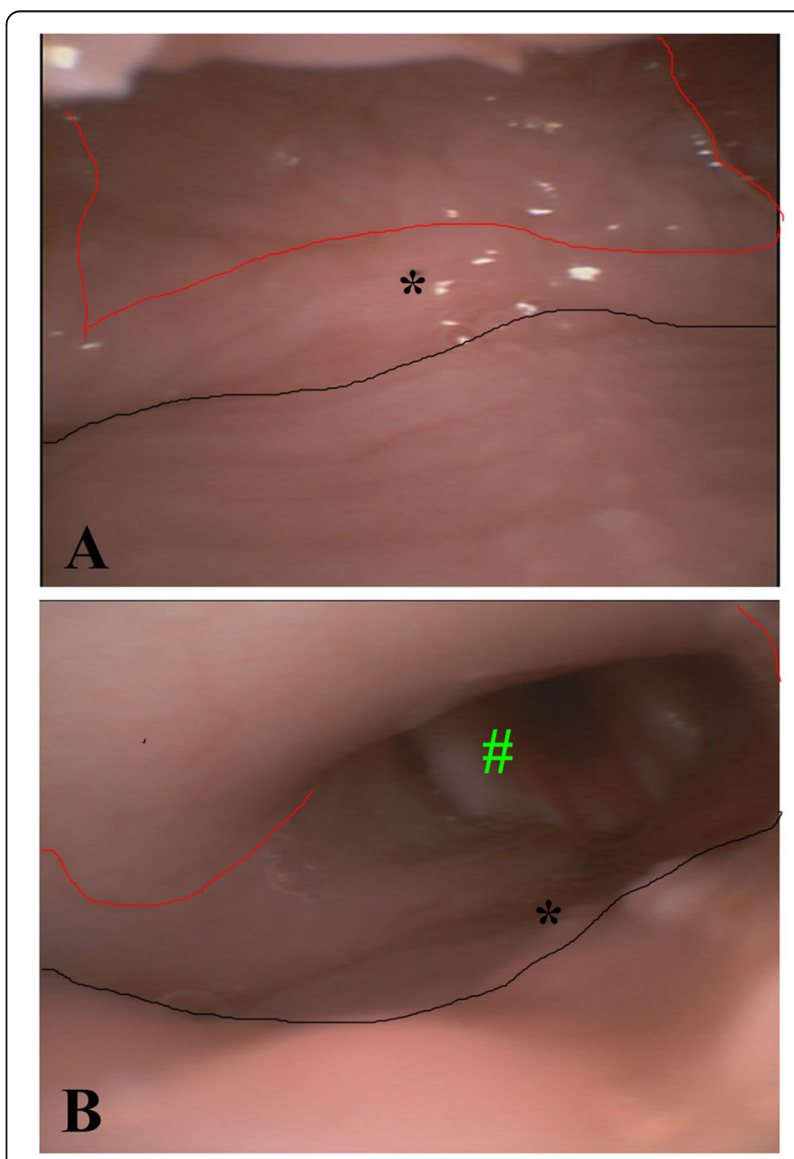

Fig. 1 Porcine laryngeal anatomy in supine position before (a) and after mobilisation of the epiglottis (b). Before mobilisation, the epiglottis (red line) is fixated behind transitional tissue between the hard palate (black line) and the soft palate ${ }^{*}$ ). After mobilisation, the epiglottis usually stays slightly ventrally dislodged and the larynx (green \#) can easily be identified 
Ambu GmbH, Bad Nauheim, Germany) using a standard TT (ID $7.0 \mathrm{~mm}$ ).

An exemplary video of FFI taken during the trial is available in the supplemental material of this article. As participants we used 3rd year medical students who had undergone basic training in animal handling in the university's Translational Animal Research Center and were approved by the State and Institutional Animal Care Committee. The participants had been introduced to large animal experiments and conventional intubation (mean of performed CIs: 4.5) for 3 months prior to the trial. A short explanation and standardized introduction to the FFI device was performed by the supervisor before the first use. None of the participants had used a flexible video-endoscope before or seen a FFI over a video monitor.

Intubation times were measured using a stopwatch beginning with the particular instrument entering the snout of the animal and were stopped when the connected ventilator revealed the first adequate capnography curve. Intubation attempts were aborted, when oxygen saturation dropped below 93\% and animals were then mask ventilated again for 3 minutes until saturation recovered before the next try. Number of attempts until successful intubation of the trachea were counted. First pass success was noted separately. After a third unsuccessful attempt, an experienced supervisor performed the intubation.

After the intervention, the animals were ventilated, allowed to recover for $30 \mathrm{~min}$ and were then assigned to the primary research projects of our facility in order not to needlessly sacrifice them and adhere to ARRIVE and $3 R$ guidelines.

\section{Statistics}

The presented study was conducted as a pilot since no adequate data on the topic could be consulted to perform a sample size calculation. Statistical analyses were performed using the Mann-Whitney-U test via GraphPad Prism 8 software (GraphPad Software Inc., La Jolla, CA, USA) assuming a non-normal distribution. Data are presented as mean (standard deviation). $P$-values $<0.05$ were considered significant.

\section{Results}

All 30 animals survived the intervention in good health and no problems were encountered at any time during mask ventilation, even if tracheal intubation proved difficult. Accordingly, all animals were available for the respective primary research project without any restrictions. In the FFI group, a higher first pass success rate ( $75 \%$ vs. $47 \%$ ) and significantly less intubation attempts were protocolled than in the CI group $(1.3 \pm 0.6$ vs. $2.1 \pm 1.3, P=0.043$, Fig. 2). Intervention by a supervisor to perform tracheal intubation was necessary twice in the CI group, whereas no interventions were necessary in the FFI group. Successful intubation attempts were significantly shorter in the CI group than in the FFI group ( $42 \mathrm{~s} \pm 6 \mathrm{~s}$ vs. $67 \mathrm{~s} \pm 10 \mathrm{~s}, P<0.001$, Fig. 2 ). Intubations were performed by a total of four participants with two supervisors assessing the data and controlling the experiments. No correlations over time regarding improved performances of the individual students could be detected.

\section{Discussion}

This study shows that FFI can be performed with a higher success rate and a better first pass success in inexperienced providers than conventional intubation by a MacIntosh blade in swine. It is the first trial to prospectively evaluate the potential benefits towards airway management using FFI in an experimental design in swine that support FFI as a reasonable method for
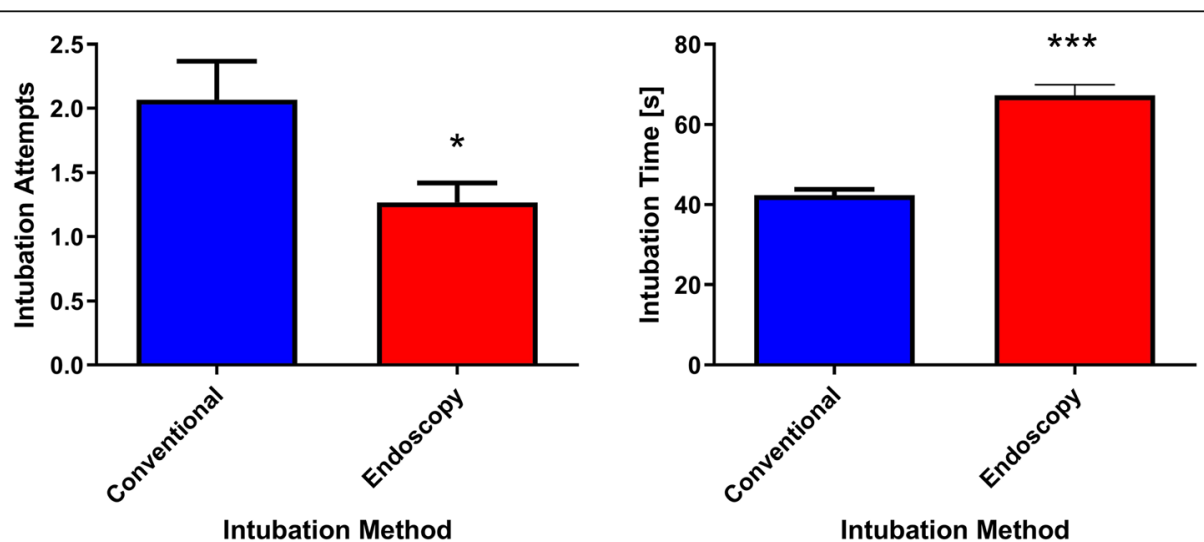

Fig. 2 Data assessment of the trial. Number of attempts (left) and time to successful intubation (right) compared by intubation method ( $n=15$ per group). With the endoscopic technique, significantly less intubation attempts were necessary (*: $P=0.043$ ). Successful video-endoscopic intubation took more time per attempt until adequate ventilation was completely established (***:P<0.001) but showed less desaturation episodes. Statistical analyses were performed using the Mann-Whitney U test 
intubation. Furthermore, a practical and efficient approach to student and resident training at the same time is described and evaluated. Our results suggest significantly less problems with the establishment of a secure airway when provided with a FFI device compared to CI. This effect proved significant in inexperienced providers as shown by the limited amount of attempts needed to place a tracheal tube. Simultaneously, first pass success rate was distinctly increased when a FFI device was used, suggesting less stress for the animal, less hypoxic episodes during induction and, subsequently, less potentially confounding factors tainting research results.

FFI required a longer intubation time when compared to CI. However, this had no clinically relevant effect. The described prolongation was most likely due to device handling, coordination with the video monitor as well as the time needed to verify tube positioning, since ventilation in our experimental setup could not be initiated before the endoscope had been removed from the tube. A longer time to intubation using endoscopic devices is common when compared to $\mathrm{CI}$ in humans $[20,21]$. However, the time to intubation using FFI significantly improves through training and expertise [21, 22]. Furthermore, a shorter time to ventilation by FFI is possible by using respiratory adapters to facilitate ventilation during endoscopy [23].

Teaching and training health care providers to adequately apply flexible endoscopes for intubation purposes is technically challenging, expensive and time-consuming $[16,20]$. Manikins as well as virtual reality simulators are reliable training methods for FFI and can facilitate skill maintenance $[15,24]$. In inexperienced providers, reported times until successful FFI compass $80 \mathrm{~s}$ [24] up to $260 \mathrm{~s}$ [15], whereas success rates are cited from $50 \%$ before training and $80 \%$ after virtual reality training [24]. On the one hand, this data is based on different study designs and obviously cannot be compared with the porcine model. On the other hand, there is a trend that swine can be intubated more quickly using FFI than the airway models currently used.

One common training opportunity in clinical routine for residents is the awake FFI in patients with anticipated difficult airway. This collective is found in ear-nose-throat and maxillofacial surgery to a higher degree than in other surgical disciplines [25]. However, various national guidelines considerably differ concerning the indication of awake FFI. Moreover, local protocols and clinical routine often does not foster FFI. Thus, structured and sufficient training programs have to rely on manikins and other models as well [22]. Animal models are perceived as more realistic compared to manikins, suggesting benefits during resident training [17]. Our model could not only provide the opportunity to perform airway management training, but, in contrast to clinical approaches, more than one provider could also be trained on the same animal subsequently and repeat the procedure multiple times, offering a more efficient way to gain proficiency in device handling. Additionally, the use of a video monitor allows a supervisor to directly teach the procedure, thus potentially improving the experience even further. Single-use bronchoscopes, as shown in our trial, can also be used repeatedly to decrease material costs. Alternatively, following our own protocol, an established research facility could schedule regular short intubation trainings during the induction of their animals with the possibility to further use the animal for protocol purposes as needed afterwards. This obviously depends on experimental setups and possible confounding effects on specific studies but might be valid in some cases. Since this would decrease animal numbers by dual-use in research and education, institutional approval to respective protocol addenda should not be problematic.

Using endoscopic techniques for tracheal intubation in animals is sophisticated and rarely used, but reports in rodents [26], ruminants [27], swine [17] and more exotic animals [28] have been previously published. Interestingly, the last - and to the best of our knowledge - only published scientific use of FFI in swine was 30 years ago by Forbes et al., who not only proved feasibility, but concluded that training with a live porcine model was more realistic and had a greater clinical benefit for students and residents [17]. Unfortunately, the topic was never properly examined again, although porcine models have become an invaluable asset in translational research, especially of systemic diseases like sepsis and ARDS $[29,30]$ and are regularly established at university hospitals and research facilities. Most of these models usually rely on tracheal intubation [10, 12, 31], although some either resort to surgical airways, i.e. tracheostomy [32, 33], or supraglottic devices [34, 35]. However, tracheal intubation of pigs can be difficult and success depends on experience, expertise and correct preparation [12, 19]. Laryngeal anatomy of supine piglets can be challenging due to a hypermobile larynx, a long snout, deep perilaryngeal recesses and a long epiglottis that usually blocks direct access to the airway in sedated animals $[9,10]$. The significantly longer oral cavity compared to humans can make it hard to visualize the epiglottis, which is long, U-shaped and often lodged on the soft palate. However, from the authors' experience, it is usually feasible to use conventional laryngoscopes (size 4) for adequate visualization and then mobilize the lodged epiglottis with a guide rod by carefully inserting it along the soft palate in the right or left piriform recess and then perform a scooping motion to the opposite side to mobilize it. Once mobilized, as long as the animal is not repositioned, the epiglottis usually does not lodge again and intubation and visualization should be easily feasible. 
Complications and mortality associated with intubation in pigs have not been comprehensively described yet, but difficult airway management is regularly mentioned [9-11]. This includes the loss of research animals during induction $[13,14]$ suggesting underreporting and maybe the basis of a general confounder of animal airway studies. The determined failure rate to intubate on the first attempt of over $50 \%$ in our study seems high, but retrospective analysis of our own research projects also suggests rates between 25 and $40 \%$. The additional increase in this trial can easily be attributed to the lack of intubation experience of the performing participants. Furthermore, TTs with a diameter of $7 \mathrm{~mm}$ are relatively large compared to standard procedures suggested by other research groups $[8,19]$. While this may have caused an increased failure rate in the $\mathrm{CI}$ group compared to smaller tubes, successful placement following FFI suggests a technique-related problem and not an anatomical one. Especially research protocols relying on low ventilation pressures and decreased lung stress could benefit from the possibility to use larger bore tubes. Since piglets can be easily ventilated non-invasively with a suitable mask, intubation problems rather represent a time factor than an actual hazard, delaying eventual tube placement. However, as more intensive manipulation is necessary to establish the airway during $\mathrm{CI}$, increased stress and hypoxia-induced changes might affect the results of planned projects. Since no data on this cause-effect relation exist, this remains speculative. Nonetheless, our study suggests a potentially systematic benefit of a FFI approach to porcine models, which could improve scientific accuracy of experimental results. This would simultaneously decrease the animal numbers needed, thus warranting the additional economical effort of establishing the infrastructure necessary.

\section{Conclusion}

Video-enhanced flexible fibreoptic intubation is an excellent method to safely secure the airway in swine. It can be used to provide more realistic training conditions for inexperienced providers and may simultaneously prevent airway complications, negative experimental effects and unnecessary animal losses in translational research.

\section{Supplementary information}

Supplementary information accompanies this paper at https://doi.org/10. 1186/s12871-020-01127-2.

Additional file 1. Video recorded with the Ambu aScope ${ }^{\text {TM }}$ system. The video depicts laryngeal passage after epiglottis mobilisation (see Fig. 1) and endotracheal insertion of the endoscope. Note the narrow space available to pass the larynx and the anatomical angle of the trachea. Porcine tracheas tend to be longer than in humans. Additionally, the upper main bronchus usually parts above the carina (00:37). This has to be considered to prevent inadequate placement of the tracheal tube. The endoscope should not be removed until definitive visualisation of the correct tube positioning was successful.

\section{Acknowledgements}

Excerpts of this study are part of the professorial dissertation (habilitation) of RR.

\section{Authors' contributions}

RR and EKH designed and supervised the experiments. AZ, TO and DD conducted the experiments and helped analyse the data. RR wrote the article, EKH and TO revised and approved the final draft. The author(s) read and approved the final manuscript.

\section{Funding}

Parts of this study were funded by the German Research Foundation (Deutsche Forschungsgemeinschaft, DFG, grant no.: RU 2371/1-1). No further external funding was used. Open access funding provided by Projekt DEAL.

\section{Availability of data and materials}

All relevant data are presented in the manuscript. Further data can be made available on reasonable request. Requests should be addressed to the corresponding author.

\section{Ethics approval and consent to participate}

The study was approved by the State and Institutional Animal Care Committee (Landesuntersuchungsamt Rheinland-Pfalz, Koblenz, Germany, approval no. G16-1-042) with an additional approval (Issue date: 8/28/2019) for the dual use of the animals in this protocol.

\section{Consent for publication}

Not applicable.

\section{Competing interests}

Ambu aScope ${ }^{\mathrm{TM}}$ and Ambu aView ${ }^{\mathrm{TM}}$ devices have been provided unconditionally for research purposes only by the manufacturer. The authors declare that there are no further conflicts of interest.

Received: 22 April 2020 Accepted: 11 August 2020

Published online: 17 August 2020

\section{References}

1. Peterson GN, Domino KB, Caplan RA, Posner KL, Lee LA, Cheney FW. Management of the difficult airway: a closed claims analysis. Anesthesiology. 2005;103:33-9.

2. Cook TM, Woodall N, Frerk C, Fourth National Audit P. Major complications of airway management in the UK: results of the fourth National Audit Project of the Royal College of Anaesthetists and the difficult airway society. Part 1: anaesthesia. Br J Anaesth. 2011:106:617-31.

3. Frerk C, Mitchell VS, McNarry AF, et al. Difficult airway society 2015 guidelines for management of unanticipated difficult intubation in adults. $\mathrm{Br}$ J Anaesth. 2015;115:827-48.

4. Schauble JC, Heidegger T. Management of the difficult airway : overview of the current guidelines. Anaesthesist. 2018;67:725-37.

5. Apfelbaum JL, Hagberg CA, Caplan RA, et al. Practice guidelines for management of the difficult airway: an updated report by the American Society of Anesthesiologists Task Force on Management of the Difficult Airway. Anesthesiology. 2013;118:251-70.

6. Piepho T, Cavus E, Noppens R, et al. S1 guidelines on airway management : guideline of the German society of anesthesiology and intensive care medicine. Anaesthesist. 2015;64(Suppl 1):27-40.

7. Law JA, Broemling N, Cooper RM, et al. The difficult airway with recommendations for management--part 2--the anticipated difficult airway. Can J Anaesth. 2013;60:1119-38.

8. Judge EP, Hughes JM, Egan JJ, Maguire M, Molloy EL, O'Dea S. Anatomy and bronchoscopy of the porcine lung. A model for translational respiratory medicine. Am J Respir Cell Mol Biol. 2014;51:334-43.

9. Dondelinger RF, Ghysels MP, Brisbois D, et al. Relevant radiological anatomy of the pig as a training model in interventional radiology. Eur Radiol. 1998;8: 1254-73.

10. Duke-Novakovski T, Ambros B, Auckland CD, Harding JC. The effects of succinylcholine or low-dose rocuronium to aid endotracheal intubation of adult sows. Can J Vet Res. 2012;76:57-61.

11. Gorti GK, Birchall MA, Haverson K, Macchiarini P, Bailey M. A preclinical model for laryngeal transplantation: anatomy and mucosal immunology of the porcine larynx. Transplantation. 1999;68:1638-42. 
12. Benson GJ. Anesthetic management of ruminants and swine with selected pathophysiologic alterations. Vet Clin North Am Food Anim Pract. 1986;2:677-91.

13. Bowman J, Juergens A, McClure M, Spear D. Intubation of the Right Atrium During an Attempted Modified Surgical Airway in a Pig. J Spec Oper Med. 2017;17:96-100.

14. Steinbacher R, von Ritgen S, Moens YP. Laryngeal perforation during a standard intubation procedure in a pig. Lab Anim. 2012;46:261-3.

15. KL R, Bautista A, Duan X, et al. Teaching basic fiberoptic intubation skills in a simulator: initial learning and skills decay. J Anesth. 2016;30:12-9.

16. Boulton AJ, Balla SR, Nowicka A, Loka TM, Mendonca C. Advanced airway training in the UK: A national survey of senior anesthetic trainees. J Anaesthesiol Clin Pharmacol. 2019;35:326-34.

17. Forbes RB, Murray DJ, Albanese MA. Evaluation of an animal model for teaching fibreoptic tracheal intubation. Can J Anaesth. 1989;36:141-4.

18. Ruemmler R, Ziebart A, Moellmann C, et al. Ultra-low tidal volume ventilation-A novel and effective ventilation strategy during experimental cardiopulmonary resuscitation. Resuscitation. 2018;132:56-62.

19. Pehbock D, Dietrich H, Klima G, Paal P, Lindner KH, Wenzel V. Anesthesia in swine : optimizing a laboratory model to optimize translational research. Anaesthesist. 2015;64:65-70.

20. Collins SR, Blank RS. Fiberoptic intubation: an overview and update. Respir Care. 2014;59:865-78 discussion 78-80.

21. Schaefer HG, Marsch SC, Keller HL, Strebel S, Anselmi L, Drewe J. Teaching fibreoptic intubation in anaesthetised patients. Anaesthesia. 1994;49:331-4.

22. Johnson C, Roberts JT. Clinical competence in the performance of fiberoptic laryngoscopy and endotracheal intubation: a study of resident instruction. J Clin Anesth. 1989;1:344-9.

23. Da Conceicao M, Genco G, Favier JC, Bidallier I, Pitti R. Fiberoptic bronchoscopy during noninvasive positive-pressure ventilation in patients with chronic obstructive lung disease with hypoxemia and hypercapnia. Ann Fr Anesth Reanim. 2000;19:231-6.

24. Boet $S$, Bould MD, Schaeffer R, et al. Learning fibreoptic intubation with a virtual computer program transfers to 'hands on' improvement. Eur J Anaesthesiol. 2010;27:31-5.

25. El-Boghdadly K, Onwochei DN, Cuddihy J, Ahmad I. A prospective cohort study of awake fibreoptic intubation practice at a tertiary Centre. Anaesthesia. 2017;72:694-703.

26. Costa DL, Lehmann JR, Harold WM, Drew RT. Transoral tracheal intubation of rodents using a fiberoptic laryngoscope. Lab Anim Sci. 1986;36:256-61.

27. Paladino L, DuCanto J, Manoach S. Development of a rapid, safe, fiber-optic guided, single-incision cricothyrotomy using a large ovine model: a pilot study. Resuscitation. 2009;80:1066-9.

28. Johnson DH. Endoscopic intubation of exotic companion mammals. Vet Clin North Am Exot Anim Pract. 2010;13:273-89.

29. Yokoyama T, Tomiguchi S, Nishi J, et al. Hyperoxia-induced acute lung injury using a pig model: correlation between MR imaging and histologic results. Radiat Med. 2001;19:131-43.

30. Wang HM, Bodenstein $M$, Duenges $B$, et al. Ventilator-associated lung injury superposed to oleic acid infusion or surfactant depletion: histopathological characteristics of two porcine models of acute lung injury. Eur Surg Res. 2010:45:121-33.

31. Steffey EP. Some characteristics of ruminants and swine that complicate management of general anesthesia. Vet Clin North Am Food Anim Pract. 1986;2:507-16

32. Kurita T, Morita K, Kazama T, Sato S. Comparison of isoflurane and propofolfentanyl anaesthesia in a swine model of asphyxia. Br J Anaesth. 2003;91:871-7.

33. Takala RS, Soukka HR, Salo MS, et al. Pulmonary inflammatory mediators after sevoflurane and thiopentone anaesthesia in pigs. Acta Anaesthesiol Scand. 2004;48:40-5.

34. Goldmann K, Kalinowski M, Dieterich J, Wulf $\mathrm{H}$. Use of the LMA-ProSeal in an experimental pig model -- a potential animal model for laryngeal mask airway research: results of a pilot study. Anasthesiol Intensivmed Notfallmed Schmerzther. 2006:41:223-7.

35. Goldmann K, Kalinowski M, Kraft S. Airway management under general anaesthesia in pigs using the LMA-ProSeal: a pilot study. Vet Anaesth Analg. 2005;32:308-13.

\section{Publisher's Note}

Springer Nature remains neutral with regard to jurisdictional claims in published maps and institutional affiliations.

Ready to submit your research? Choose BMC and benefit from:

- fast, convenient online submission

- thorough peer review by experienced researchers in your field

- rapid publication on acceptance

- support for research data, including large and complex data types

- gold Open Access which fosters wider collaboration and increased citations

- maximum visibility for your research: over $100 \mathrm{M}$ website views per year

At $\mathrm{BMC}$, research is always in progress.

Learn more biomedcentral.com/submissions 